\title{
A relação entre marcadores inflamatórios e depressão: uma revisão da literatura
}

A depressão é uma doença psiquiátrica que está cada vez mais persistente no mundo todo. Foi descrita pela primeira vez na Antiguidade e está até hoje tendo uma grande incidência de casos. Não se sabe ao certo sua fisiopatologia, porém nota-se cada vez mais que é um mal de causa multifatorial. A partir de muitos estudos realizados, já se sabe que existe uma diminuição na quantidade de neurotransmissores, como serotonina e dopamina, em relação a pacientes saudáveis. Esses neurotransmissores influenciam nossas emoções, aprendizado, humor e atenção e sua falta pode gerar o humor triste persistente. Seguindo essa lógica, estudos mais recentes demostram um aumento da quantidade de marcadores inflamatórios, como citocinas, interleucinas e PCR (proteína C-reativa), que podem atrapalhar o metabolismo de vitamina B, por exemplo, o que reduz a distribuição de serotonina, prejudicando o prognóstico de pacientes diagnosticados com transtorno depressivo. Em tais estudos, a presença exacerbada desses marcadores inflamatórios, principalmente IL-6, PCR, TNF e IL-1ß, tem sido relacionada à existência diagnosticados com transtorno depressivo. Em tais estudos, a presença exacerbada desses marcadores inflamatórios, principalmente IL-6, PCR, TNF e IL-1ß, tem sido relacionada à existência decorrente de comportamentos associados a comorbidades relacionadas à depressão, como obesidade e doenças cardiovasculares. No que tange ao tratamento da depressão, os antidepressivos são utilizados em larga escala, sendo prescritos também para outras doenças. O uso inadequado e em excesso de tal medicamento é frequente e pode ocasionar diverso efeitos colaterais, como alta cardiotoxicidade, o que, segundo estudos, pode levar ao aumento dos marcadores inflamatórios sistêmicos, conforme o tipo de medicamento. Nesses estudos, o uso de antidepressivos tricíclicos (ADTs) resultariam em altos níveis de marcadores inflamatórios. Em contrapartida, outros estudos contrários demonstram que o uso de inibidores seletivos de recaptação de serotonina (ISRS) estaria relacionado à redução dos níveis de marcadores inflamatórios. Diante dessas divergências, novos estudos são feitos, a fim de relacionar o aumento no número de marcadores inflamatórios ao desenvolvimento da depressão, que deve ser investigado para ser utilizado como biomarcador clínico para depressão, contribuindo para o diagnóstico, monitoramento, prognóstico e tratamento da doença de forma eficaz.

Palavras-chave: Marcadores inflamatórios; Citocinas; Biomarcadores; Depressão; Neuroinflamação.

\section{The relation between inflammatory markers and depression: $a$ literature review} \begin{abstract}
Depression is a psychiatric illness that is increasingly persistent worldwide. It was first described in Antiquity and is still having a high incidence of cases. Its pathophysiology isn't well known, but it's increasingly noticed that it is a multifactorial disease. From many studies conducted, it is already known that there is a variation in the number of neurotransmitters, such as serotonin
and dopamine, compared to healthy patients. These neurotransmitters influence our emotions, learning, mood and attention and their lack can generate persistent sadness. Following this logic, more recent studies show an increase in the amount of inflammatory markers, such as cytokines, interleukins and CRP (C-reactive protein) that, for example, can disrupt vitamin B metabolism, which reduces the distribution of serotonin, impairing the prognosis of patients diagnosed with depressive disorder. In these studies, the exacerbated presence of these inflammatory markers, mainly IL-6, CRP, TNF and IL-1ß, has been related to the presence of depressive symptoms, such as fatigue and impaired sleep. However, in contrary studies to the theory that relates immune dysregulation to depression, inflammation is explained as a factor resulting from behaviors associated with depression-related comorbidities, such as obesity and cardiovascular diseases. Regarding the treatment of depression, antidepressants are used on a large scale and are also prescribed for other diseases. The inappropriate and excessive use of such medication is recurrent and can cause seeval side effects, such as high cardiotoxicity, which, according to studies, can lead to an increase in systemic inflammatory markers, according use of selective serotonin reuptake inhibitors (SSRI) would be related to the reduction of the levels of inflammatory markers. In view of these divergences, new studies are being carried out in order to relate the increase of inflammatory markers to the development of depression, which has been investigated to be used as a clinical biomarker for depression, contributing to the diagnosis of the disease and the prescription of an effective treatment.
\end{abstract}

Keywords: Inflammatory markers; Cytokines; Biomarkers; Depression; Neuroinflammation.

Topic: Neurologia e Neurociências

Reviewed anonymously in the process of blind peer
Received: $17 / 10 / 2020$

Approved: 19/01/2021
Davi Benevides Almeida (iD)

Centro Universitário Christus, Brasil

http://lattes.cnpq.br/6882755730017191

http://orcid.org/0000-0002-7421-4904

davi.benevidesps@gmail.com

Stéphanie Chrystine Balestro Mota

Centro Universitário Christus, Brasil

http://lattes.cnpq.br/3028672782885150

http://orcid.org/0000-0001-7540-9650

stephanie.chrystine@gmail.com

Dara da Silva Mesquita (iD

Universidade Federal do Ceará, Brasil

http://lattes.cnpq.br/6780805732812263

http://orcid.org/0000-0002-8186-8375

daramesq@gmail.com

\section{José Eduardo Ribeiro Honório Júnior (iD \\ Centro Universitário Christus, Brasil \\ http://lattes.cnpq.br/4272610021115688 \\ http://orcid.org/0000-0001-8320-8525}

jose.ribeiro@unichristus.edu.br
Referencing this:

ALMEIDA, D. B.; MOTA, S. C. B.; MESQUITA, D. S.; HONÓRIO JÚNIOR, J. E. R.. A relação entre marcadores inflamatórios e depressão: uma revisão da literatura. Scire Salutis, v.11, n.1, p.84-97, 2021. DOI: http://doi.org/10.6008/CBPC2236-9600.2021.001.0010 


\section{INTRODUÇÃO}

A depressão é uma doença que atinge diversas pessoas no mundo todo e está cada vez mais se tornando um problema de saúde pública. Segundo os dados mais recentes da Organização Mundial da Saúde (OMS), de 2015, cerca de 322 milhões de pessoas sofrem desse mal e 48\% delas são habitantes do Sudeste Asiático e da região do Pacífico Ocidental, abrangendo países como Austrália, China e Índia. Existe uma certa prevalência na população feminina de faixa etária entre 45 e 79 anos. Menezes (2015) explica que essa diferença entre gêneros pode ser devido às influências hormonais comuns às mulheres, como as fases do ciclo menstrual, o uso de contraceptivos, a menopausa e o uso de estrógenos.

Dias (2017) ressalta que a prevalência da depressão no Brasil é maior quando comparada com outros países. Estima-se que $28,27 \%$ da população brasileira apresenta sintomas relacionados à depressão e a prevalência na população idosa é de $34,9 \%$. Entre todos os idosos do Brasil, 19,1\% são diagnosticados com depressão grave, o que demostra uma taxa mais elevada em comparação com outros países.

Diversos estudos foram feitos para explicar a fisiopatologia da depressão, porém ainda não se sabe com precisão as causas da doença. Nessa perspectiva, algumas teorias foram postuladas para explicar tais origens, como a teoria monoaminérgica, na qual o principal fator decorrente da depressão seria a baixa quantidade de aminas biogênicas cerebrais, como a serotonina e a dopamina, ou o número ou potencial de ação dos receptores. Uma teoria destacada nos últimos anos é a da associação do sistema imune e endócrino ao sistema neural, com a participação primordial de marcadores inflamatórios relacionados aos sintomas da depressão. Tais marcadores são as citocinas pró-inflamatórias, como IL-1, IL-6, TNF- $\alpha$ e PCR (proteína Creativa), que promoveriam uma modificação na via metabólica do triptofano (aminoácido precursor da vitamina B3), reduzindo a distribuição de serotonina e levando às alterações de humor (BACELAR JÚNIOR et al., 2016).

Portanto, o objetivo deste trabalho é relacionar a depressão com a persistência ou não dos marcadores inflamatórios e assim demostrar que essa doença tem causalidade diversa, não apenas um fruto da baixa quantidade de neurotransmissores relacionados com o sistema de recompensa e o prazer.

\section{METODOLOGIA}

O trabalho consiste em uma revisão narrativa da literatura sobre a relação entre os marcadores inflamatórios e a depressão. Foi realizada uma busca de artigos científicos nas bases de dados Reference Management Software \& Researcher Network (Mendeley), Scientific Eletronic Library Online (SciELO) e Google Acadêmico (Scholar Google), usando as palavras-chave marcadores inflamatórios, citocinas, biomarcadores, depressão e neuroinflamação. Os critérios de inclusão para seleção dos artigos foram: artigos originais e de revisão, completos e atuais (publicados nos últimos cinco anos), nos idiomas português e inglês. Os critérios de exclusão foram artigos incompletos, com mais de cinco anos. Durante a busca, foram encontrados 23 artigos, dos quais 15 se encaixam nos critérios específicos de seleção. 


\section{DISCUSSÃO TEÓRICA}

\section{O histórico da depressão}

Dias (2017) relembra que há casos relatados de depressão desde a Antiguidade. Na história do primeiro rei do antigo reino de Israel, chamado Saul, o velho testamento descreve o que aparenta ser um quadro depressivo. Durante a Grécia antiga, o poeta Homero relatou um suicídio na sua obra llíada. O pai da Medicina, Hipócrates, utilizou termos que hoje se sabe estarem relacionados com o transtorno depressivo, como "melancolia". No século XIX, a depressão passou a ser considerada uma doença independente.

Dos 7,7 bilhões de pessoas que vivem no planeta, 4,3\% sofrem de depressão, sendo a terceira doença que mais acomete pessoas no mundo. Ela é basicamente caracterizada por uma tristeza que persiste por muito tempo, tendo alguma causa como gatilho ou mesmo sem causa aparente.

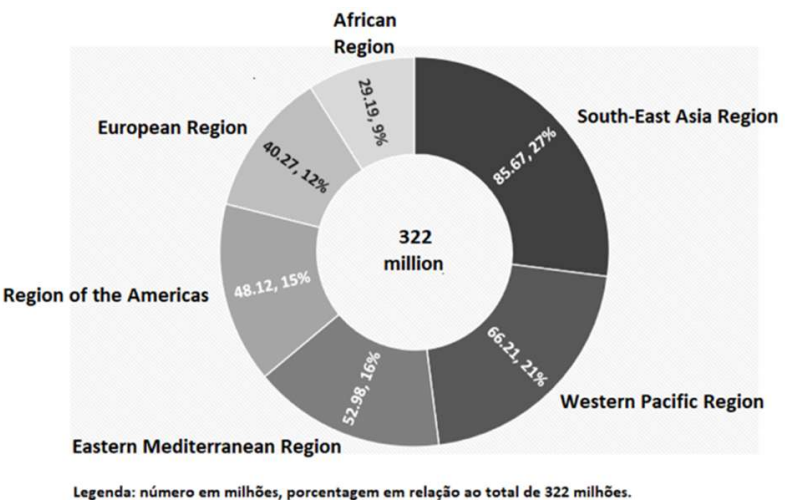

Figura 1: Casos de transtorno depressivo (milhões) divididos por regiões demarcadas pela World Health Organization

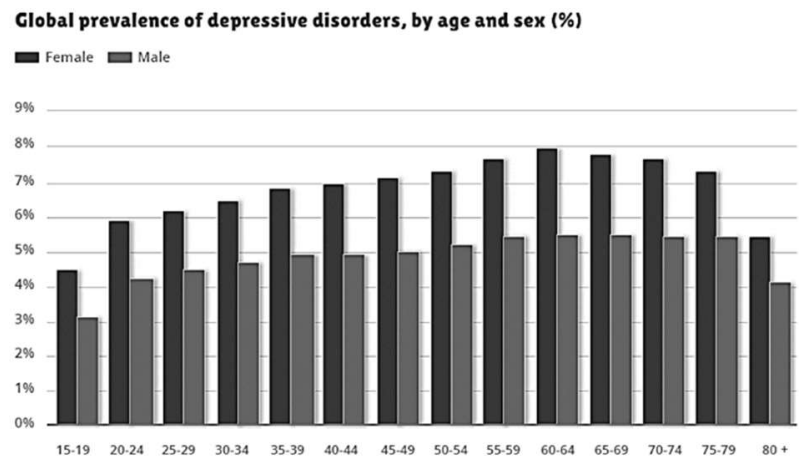

Figura 2: Prevalência (\%) global de casos separados por idade e sexo.

Fonte: WHO (2017).

\section{As possíveis fisiopatologias da depressão}

Na busca por entender a fisiopatologia da depressão, uma das primeiras hipóteses criadas foi a teoria monoaminérgica já citada, que envolve o sistema neuroendócrino. Ela se baseia na ação direta de neurotransmissores, como serotonina, dopamina e noradrenalina (as aminas biogênicas cerebrais), no sistema nervoso central. Essas substâncias estão relacionadas com o nosso sistema de recompensa e são responsáveis, entre outros fatores, pelas alterações de humor. Simplificadamente, uma alta quantidade simboliza um humor mais alegre e eufórico e uma baixa quantidade causaria um humor triste, característica principal do transtorno depressivo.

Bacelar Júnior et al. (2016) relembram que há vários estudos nos quais os pacientes com depressão demostram uma diferença no funcionamento do sistema imunológico em relação a pacientes saudáveis. Nota-se que há uma ativação da resposta imune inata e uma elevação na quantidade de citocinas próinflamatórias. Estas últimas "são indispensáveis para direcionar uma resposta inflamatória no local de infecção ou lesão" (BACELAR JÚNIOR et al., 2016).

De forma geral, citocinas não costumam causar danos à saúde do organismo, sendo benéficas em condições normais. Porém, essas substâncias podem acarretar certas consequências negativas quando 
ativadas exacerbadamente ou de forma prolongada. Quando essa ativação errônea ocorre no sistema nervoso central, ela pode estar ligada à fisiopatologia da depressão e de outros transtornos mentais. Ao atingirem o cérebro, as citocinas podem atrapalhar o metabolismo das aminas biogênicas cerebrais, influenciando sua síntese, liberação e recaptação (BACELAR JÚNIOR et al., 2016).

\section{Marcadores inflamatórios}

Os marcadores inflamatórios são mais especificamente moléculas polipeptídicas chamadas de citocinas, que são os fatores principais de uma resposta imune pró-inflamatória ou anti-inflamatória. Elas são responsáveis pela comunicação entre células, com o fito de promover uma sinalização para induzir a diferenciação, a reparação e a modulação de uma resposta imune, segundo Bacelar Júnior et al. (2016). As citocinas são moléculas benéficas, mas em casos de liberação intensa podem gerar respostas inflamatórias perigosas, sendo capaz de promover diversas patologias. As citocinas são conhecidas como fatores de necrose tumoral (TNF), interleucinas (IL), interferons (IFN) e quimiocinas. Essas moléculas podem ser próinflamatórias, responsáveis pela inflamação, como IL-1 $\alpha$, IL-2 $\beta$, TNF- $\alpha$, IL-6 e IL-8, ou anti-inflamatórias, responsáveis por cessar a resposta inflamatória, como IL-4, IL-10 e IL-13 (FREITAS, 2017). A alteração dessas citocinas pode estar relacionada a patologias e, nesses casos, ocorre paralelamente o aumento da permeabilidade da barreira hematoencefálica, sendo possível o transporte dessas citocinas para o sistema nervoso central, o que pode desencadear a ativação do sistema imune e levar a uma neuroinflamação (MACHADO et al., 2020).

Essa inflamação no sistema nervoso central (SNC) está sendo relacionada como um dos fatores da patogênese da depressão, haja vista que células como a micróglia e o astrócito (células que serão abordadas com maiores detalhes posteriormente) são responsáveis pela produção de muitas das citocinas estudadas como marcadores inflamatórios da depressão (FREITAS, 2017). Além disso, outros fatores, como o estresse oxidativo resultante da produção de intermediários reativos de oxigênio e espécies reativas de nitrogênio, estão relacionados à neuroinflamação no SNC (MACHADO et al., 2020).

Em estudos, tem-se relacionado a liberação de citocinas em excesso com mudanças no sistema neuroendócrino, participando do desenvolvimento de doenças como a depressão. Nesses estudos, marcadores inflamatórios, como IL-6, IL-1, TNF- $\alpha$ e PCR, teriam um aumento substancial em pessoas deprimidas e seriam responsáveis pela redução dos níveis de serotonina na fenda sináptica que, segundo a teoria monoaminérgica, seria a causa da depressão. Nessa perspectiva, é possível notar que as duas teorias se cruzariam e complementariam uma a outra (BACELAR JÚNIOR et al., 2016).

Apesar desses estudos apresentarem grandes indicativos da participação do sistema imune na depressão, os estudos com populações gerais são inconclusivos, de acordo com Menezes (2015). Segundo a mesma autora, a ligação depressão e inflamação poderia ocorrer devido a comportamentos relacionados à saúde decorrentes da depressão, como tabagismo, uso excessivo de álcool, obesidade, doenças cardiovasculares e diabetes. Esses fatores seriam os reais causadores do aumento do número de marcadores inflamatórios, geradores da inflamação, e não a depressão em si. Nesse sentido, chegamos a um ponto em 
que a questão discutida seria que "inflamação pode participar da fisiopatologia da depressão e a depressão pode contribuir para o desenvolvimento de um estado pró-inflamatório" (LEMOS et al., 2015).

\section{A relação sistema imune e sistema nervoso}

O sistema imune representa a linha de defesa do organismo contra patógenos externos (bactérias, vírus etc.) e lesões teciduais. É constituído pela imunidade inata: barreiras epiteliais, células apresentadoras de antígenos (APCs), fagócitos (células dendríticas, macrófagos, monócitos e neutrófilos), células Natural Killer (NK), mastócitos, basófilos, eosinófilos e sistema complemento; e pela imunidade adaptativa: linfócitos T e B (o último é produtor de anticorpos). Algumas dessas células que constituem o sistema imune são responsáveis pela secreção de citocinas, principalmente os linfócitos $T$, as células NK e os fagócitos (MACHADO et al., 2020).

Dentro de qualquer sistema ou órgão do corpo, as células imunológicas podem receber nomes específicos, dependendo do local onde atuam. No sistema nervoso central (SNC), há dois tipos de células principais: as micróglias e os astrócitos (MACHADO et al., 2020).

As micróglias são células com alta capacidade de fagocitose. Quando o sistema nervoso não se encontra em estado inflamatório, "a micróglia participa na manutenção das sinapses nervosas no SNC" (MACHADO et al., 2020). Desequilíbrios na fisiologia desse sistema levam à ativação da micróglia, que passa a ter características de uma célula do sistema imune. Em sua forma ameboide, ela facilmente se movimenta dentro do SNC e assim chega aos locais onde é necessária, sem induzir inflamação. Na sua forma ativa, ela "tem alta habilidade em fagocitose e apresentação de antígenos" (MACHADO et al., 2020) e passa a produzir citocinas pró-inflamatórias, como TNF- $\alpha$ e IL-1, provocando uma neuroinflamação.

Os astrócitos auxiliam no transporte das micróglias ameboides aos locais de inflamação. Além disso, eles capturam glutamato (um neurotransmissor excitatório) e evitam o seu acúmulo no tecido nervoso, capaz de gerar certa neurotoxicidade (MACHADO et al., 2020).

\section{Marcadores inflamatórios e neuroinflamação}

Como citado anteriormente, as citocinas são proteínas liberadas por células do sistema imune inato e adquirido e são produzidas pelos monócitos nesses sistemas (FREITAS, 2017). Caso essas proteínas periféricas sejam levadas até o sistema nervoso central, elas podem gerar uma inflamação, produzindo, dessa forma, mais citocinas dentro do tecido nervoso.

Sendo assim, a proteína C-reativa (PCR) é um exemplo e tem como função principal o reconhecimento de patógenos e células danificadas, para assim eliminá-las. Ela é produzida por estímulos de TNF- $\alpha$ e IL-6 e seu aumento ocorre em resposta a processos inflamatórios gerados por diversas morbidades. Segundo Menezes (2015), doenças, como obesidade, resistência à insulina e diabetes mellitus, têm relação com o aumento de níveis de PCR, assim como o uso de contraceptivo e terapia de reposição hormonal pósmenopausa. A PCR também foi sondada em meta-análises com pacientes que sofriam de depressão maior e, segundo Bacelar Júnior et al. (2016), foi visto que o aumento do nível de PCR estava associado ao aumento 
do risco de depressão, além de que também foram indicados aumentos nos níveis de IL-6, TNF- $\alpha$ (precursores da PCR) e IL-1, demonstrando ligação com essa doença.

A IL-1 $\beta$ e o TNF- $\alpha$ são descritos na literatura como citocinas pró-inflamatórias capazes de bloquear dor, elevar o estresse, fadiga e depressão. A IL-1ß é um mediador inflamatório primário e provoca a formação de IL-6, IL-8 e INF- $\gamma$, citocinas já citadas anteriormente como pró-inflamatórias. Recentemente, um estudo transversal feito no Brasil também identificou o aumento considerável nos níveis séricos de IL-1 $1 \beta$ e do receptor solúvel 2 do TNF em idosas deprimidas (DIAS, 2017). No entanto, nessa pesquisa não foram observadas mudanças nas citocinas pró e anti-inflamatórias entre idosas com transtorno depressivo maior e controles, porém, foi relatado que existe uma relação entre a gravidade dos sintomas depressivos e os níveis plasmáticos de TNF, IL-2, IL-5 e IL-10, na qual pacientes idosas depressivas com sintomas "moderados a graves" demonstraram aumento nos níveis de TNF, IL-5 e IL-10; já os pacientes com sintomas "leves" não tiveram esse desequilíbrio, o que levou a autora a levantar a seguinte hipótese: "quanto maior a gravidade de sintomas depressivos, maiores os níveis de marcadores inflamatórios (IL-5 e TNF) quanto antiinflamatórios (IL-10)". Segundo a autora, essa diferença seria dada pela narrativa sobre a vida dos pacientes com TDM, na qual casos moderados a graves teriam lidado com a doença por mais tempo, gerando um número maior de alterações biológicas relevantes, ao contrário de pacientes com TDM leve, que estariam com sintomas a menos tempo e, portanto, teriam menos tempo de doença, levando-os a ter menores alterações biológicas consideráveis (DIAS, 2017).

A TNF- $\alpha$ tem sido muito estudada e a maioria dos estudos que relacionam marcadores inflamatórios e depressão demonstra sua relevância, por conta do aumento dos seus níveis séricos, juntamente com a IL6 e o IL-1 $\beta$, destacado anteriormente. Tal citocina é induzida por outras pró e anti-inflamatórias, o que leva a um processo de inflamação aguda. De acordo com Bacelar Júnior et al. (2016), existe a possibilidade de que a inflamação, demonstrada nos altos níveis de TNF- $\alpha$, IL-6 e IL-1 $\beta$, esteja vinculada ao desenvolvimento da depressão em pacientes com doença de Parkinson.

Já a IL-6 está relacionada à inflamação em diversas doenças, como diabetes mellitus e artrite reumatoide, e, como já foi dito anteriormente, também tem grande notoriedade nos estudos de depressão e marcadores inflamatórios. Segundo o estudo de Dias (2017), os níveis plasmáticos de IL-6 em idosas com TDM é maior em relação ao controle, e esse aumento também é relatado em outros estudos e com uma diferença estatisticamente importante. Em contrapartida, outros estudos demonstraram que os níveis dessa citocina estavam reduzidos em idosas deprimidas comparados a controles (DIAS, 2017). A autora considera que a alta atividade do sistema imunológico de idosos deprimidos pode levar à exaustão biológica, causando a redução dos níveis de IL-6. Na revisão sistemática de Freitas (2017) foi contestado que a IL-6 teria uma diminuição significativa após o uso de antidepressivo, o que pode levar a entender que tal citocina está relacionada à depressão.

Diante do que foi apresentado, é possível perceber que ainda é difícil compreender completamente e chegar a um resultado conclusivo quanto à inflamação, a seus marcadores e à ligação com a depressão. No entanto, algo notável é a grande quantidade de evidências de que o aumento dos níveis de marcadores 
inflamatórios poderia estar relacionado ao desenvolvimento da depressão. Nesse sentido, vem-se estudando a implementação dos marcadores como biomarcadores da depressão.

Quadro 1: Comparação dos artigos com estudos clínicos de marcadores inflamatórios.

\begin{tabular}{|c|c|c|c|}
\hline Estudo & Metodologia & Possíveis vieses & Resultados \\
\hline $\begin{array}{l}\text { Menezes } \\
\text { (2015) }\end{array}$ & $\begin{array}{l}\text { - } 14.821 \text { participantes: } 35-74 \text { anos } \\
\text { entre } 2008 \text { e } 2010 \text { (coorte ELSA- } \\
\text { Brasil); } \\
\text { - } 6 \text { estados brasileiros: Minas Gerais, } \\
\text { São Paulo, Rio de Janeiro, Espírito } \\
\text { Santo, Bahia e Rio Grande do Sul; } \\
\text { - Depressão nos últimos } 7 \text { dias, } \\
\text { combinada ou não com } \\
\text { antidepressivos; } \\
\text { - Depressão avaliada pelo Clinical } \\
\text { Interview Schedule - Revised; } \\
\text { - Características sociodemográficas, } \\
\text { comportamentos de saúde e } \\
\text { comorbidades como covariáveis; } \\
\text { - Medição dos níveis séricos de PCR; } \\
\text { - Associação de uma classe específica } \\
\text { de antidepressivo aos níveis de PCR. }\end{array}$ & $\begin{array}{l}\text { - A pesquisa não se estendeu à } \\
\text { população mais jovem; } \\
\text { - PCR como único marcador } \\
\text { inflamatório analisado; } \\
\text { - Não foram descritos a forma de } \\
\text { coleta do material biológico, } \\
\text { assim como o método utilizado } \\
\text { para a medição dos níveis de } \\
\text { PCR. }\end{array}$ & $\begin{array}{l}\text { - A depressão isolada, combinada ou } \\
\text { não com o uso de antidepressivos, e } \\
\text { o uso de antidepressivo isolado não } \\
\text { apresentaram um resultado } \\
\text { associado a altos níveis de PCR no } \\
\text { sangue; } \\
\text { - Os resultados foram ajustados por } \\
\text { sexo, idade e escolaridade; } \\
\text { - A entrada das covariáveis não } \\
\text { alterou o resultado; } \\
\text { - A análise de acordo com o tipo e } \\
\text { gravidade da depressão e a } \\
\text { estratificação por sexo também não } \\
\text { alterou o resultado. }\end{array}$ \\
\hline $\begin{array}{l}\text { Dias } \\
(2017)\end{array}$ & $\begin{array}{l}\text { - } 45 \text { sujeitos do sexo feminino: } 60 \\
\text { anos ou mais; } \\
\text { - } 25 \text { com diagnóstico de TDM; } \\
\text { - } 20 \text { controles saudáveis; } \\
\text { - Avaliação da depressão pelo Mini- } \\
\text { International Neuropsychiatry } \\
\text { Interview (MINI-Plus) e pela escala de } \\
\text { depressão de Hamilton (HAM-D); } \\
\text { - Marcadores inflamatórios } \\
\text { avaliados: IL-6, IFN- } \alpha \text {, IFN- }- \text {, TNF-, IL- } \\
\text { 2, IL-4, IL-5 e IL-10; } \\
\text { - Avaliação da tendência de a } \\
\text { resposta ser pró-inflamatória ou anti- } \\
\text { inflamatória; } \\
\text { - Avaliação da tendência entre as } \\
\text { respostas Th1 e Th2; } \\
\text { - Coleta do sangue periférico após } \\
\text { avaliação psiquiátrica (o material } \\
\text { biológico foi bem captado e } \\
\text { armazenado); } \\
\text { - Kit HCYTOMAG-60k e análise } \\
\text { laboratorial pela técnica do Luminex, } \\
\text { seguindo as orientações dos } \\
\text { fabricantes. }\end{array}$ & $\begin{array}{l}\text { - Limitação da população para } \\
\text { pacientes idosos do sexo } \\
\text { feminino (com } 65 \text { anos ou mais); } \\
\text { - População pequena, de apenas } \\
45 \text { pessoas; } \\
\text { - Não foram analisados dados } \\
\text { que dizem respeito ao início dos } \\
\text { sintomas depressivos e a } \\
\text { quantidade de episódios ao } \\
\text { longo da vida. }\end{array}$ & $\begin{array}{l}\text { - Pacientes com TDM apresentam um } \\
\text { aumento de IL-6 em comparação com } \\
\text { controles; } \\
\text { - Não há diferença em relação a IFN- } \\
\alpha \text {, IFN- } \gamma \text {, TNF, IL-2, IL-5 e IL-10; } \\
\text { - Há um equilíbrio entre as respostas } \\
\text { pró-inflamatória e anti-inflamatória e } \\
\text { respostas Th1 e Th2 entre pacientes e } \\
\text { controles; } \\
\text { - Pacientes com TDM moderado a } \\
\text { grave possuem um aumento na } \\
\text { quantidade de TNF em comparação } \\
\text { com pacientes com TDM leve; } \\
\text { - Há um equilíbrio entre as respostas } \\
\text { pró-inflamatória e anti-inflamatória e } \\
\text { respostas Th1 e Th2 entre esses dois } \\
\text { grupos acima. }\end{array}$ \\
\hline $\begin{array}{l}\text { Schmitt } \\
\text { Júnior et } \\
\text { al. (2018) }\end{array}$ & $\begin{array}{l}\text { - Pacientes do Hospital de Clínicas de } \\
\text { Porto Alegre (HCPA); } \\
\text { - } 92 \text { pacientes com Depressão } \\
\text { Unipolar; } \\
\text { - } 26 \text { pacientes com Depressão } \\
\text { Bipolar; } \\
\text { - } 44 \text { pacientes com Mania; } \\
\text { - } 44 \text { pacientes com Esquizofrenia; } \\
\text { - } 100 \text { controles saudáveis; } \\
\text { - Total de } 206 \text { pessoas (106 com } \\
\text { doença mental grave); } \\
\text { - Medição de marcadores } \\
\text { inflamatórios na admissão e na alta } \\
\text { hospitalar; } \\
\text { - Marcadores: IFN- } \gamma \text {, TNF- } \alpha \text {, IL-2, IL-4, } \\
\text { IL-6, IL-10 e IL-17. }\end{array}$ & $\begin{array}{l}\text { - Limitação a pacientes de um } \\
\text { único hospital e de uma única } \\
\text { cidade e região do Brasil; } \\
\text { - Baixa população total. }\end{array}$ & $\begin{array}{l}\text { - Pacientes com transtornos mentais } \\
\text { graves tiveram níveis séricos dos } \\
\text { marcadores inflamatórios mais } \\
\text { elevados em relação a controles; } \\
\text { - Não houve redução significativa dos } \\
\text { níveis de IFN- } \gamma \text {, TNF- } \alpha \text {, IL-4, IL-10 e IL- } \\
17 \text { em nenhum dos diagnósticos } \\
\text { avaliados; } \\
\text { - Apenas os pacientes com depressão } \\
\text { maior tiveram uma diminuição dos } \\
\text { níveis de IL-2 e IL- } 6 \text { de forma } \\
\text { significativa entre a admissão e a alta } \\
\text { hospitalar. }\end{array}$ \\
\hline
\end{tabular}




\section{A barreira hematoencefálica e o seu papel na neuroinflamação}

Aquino (2019) e Sobral (2018) concordam que a barreira hematoencefálica (BHE) foi primeiramente descoberta em 1885 por Paul Ehrlich (1854-195). Ele injetou uma substância com corante dentro da circulação sanguínea periférica e percebeu que todo os vasos do organismo coravam, com exceção do SNC. Aquino (2019) e Sobral (2018) relatam que Goldmann (em 1913), além de repetir o teste de Paul, fez um experimento contrário: injetou um corante diretamente no SNC e percebeu que apenas o tecido nervoso corava, deixando o resto do corpo livre do corante.

Sendo assim, a BHE é uma estrutura de extrema importância para a manutenção do bom funcionamento do SNC, pois impede a passagem de substâncias tóxicas presentes no sangue para o encéfalo e a medula espinhal e vice-versa (SOBRAL, 2018). Aquino (2019) afirma que "a BHE já se encontra completamente formada ao nascimento", sendo composta por um sistema celular complexo. Segundo a autora, a permeabilidade da BHE é restritamente seletiva, permitindo apenas a passagem de substâncias necessárias para manter a homeostasia do cérebro, além de nutrir diretamente o sistema nervoso central. “O SNC não pode tolerar e continuar sua função diante de um ambiente com flutuações na concentração de substâncias neuroativas" (AQUINO, 2019), flutuações que ocorrem de forma rotineira na circulação sanguínea após uma refeição ou exercício físico.

Varatharaj et al. (2017) explicam que uma inflamação sistêmica é capaz de gerar alterações na permeabilidade da barreira hematoencefálica, podendo essas alterações serem de caráter disruptivo e não disruptivo.

As alterações disruptivas ocorrem a nível histológico, com mudanças na anatomia e estrutura da BHE, podendo ser detectada com marcadores inertes e geralmente não há afinidade com alguma substância específica. Nesse tipo, grandes moléculas são capazes de passar pela barreira mais facilmente e o transporte transmembrana é mais fácil. Danos aos endotélios da BHE costumam causar esse tipo de lesão, o que aumenta significamente a permeabilidade dessa barreira (SOBRAL, 2018; VARATHARAJ et al., 2017).

As alterações não disruptivas ocorrem a nível molecular, sem mudanças anatômicas e estruturais, pois há alteração na função. Não é detectada usando marcadores inertes e sempre há afinidade com alguma substância específica. Por exemplo, as proteínas transmembranas de transporte podem aumentar a expressão dos seus receptores, atraindo, para o interior da BHE, uma quantidade excessiva da substância correspondente a essa proteína. Citocinas sistêmicas, como IL-1 $\beta$ e TNF- $\alpha$, ao entrarem em contato com a barreira hematoencefálica, podem ativar as células endoteliais cerebrais, que passam a produzir IL-1 $\beta$, IL-6 e TNF- $\alpha$. Essas citocinas pró-inflamatórias entram em contato direto com o tecido nervoso, causando neuroinflamação. Por outro lado, se as células endoteliais produzirem IFN- $\beta$, ele reduz a migração de linfócitos com resposta Th1, diminuindo a atividade inflamatória na região (VARATHARAJ et al., 2017). 


\section{Diagnóstico da depressão}

Em 2014, a American Psychiatric Association (APA) publicou o Manual Diagnóstico e Estatístico de Transtornos Mentais: DMS-5, 5ạ edição. Esse manual, resultado de um trabalho de 10 anos, teve o envolvimento de especialistas de todo o mundo, trazendo, assim, o que há de mais atual sobre o tema. Nele, há certos critérios para se diagnosticar o transtorno depressivo maior (TDM), listados no quadro a seguir:

Quadro 2: Critérios do DSM-5 para definição de transtorno depressivo maior.
A) No mínimo, cinco dos seguintes sintomas devem estar presentes durante o período mínimo de duas semanas e representam uma alteração a partir do funcionamento anterior. Pelo menos um dos sintomas deve ser: (1) humor deprimido ou (2) perda do interesse ou prazer.
A) Nota: não incluir sintomas nitidamente devidos a uma condição médica geral, alucinações ou delírios incongruentes com o humor.
1. Humor deprimido na maior parte do dia, quase todos os dias. Indicado por relato subjetivo ou observação feita por outros.
2. Acentuada diminuição do interesse ou prazer em todas ou quase todas as atividades, na maior parte do dia, quase todos os dias. Indicado por relato subjetivo ou observação feita por outros.
3. Perda ou ganho significativo de peso sem estar em dieta (exemplificado por mais de $5 \%$ do peso corporal em 1 mês). Pode ser considerado diminuição ou aumento do apetite quase todos os dias.
4. Insônia ou hipersonia quase todos os dias.
5. Agitação ou retardo psicomotor quase todos os dias. Observáveis por outros, não meramente sensações subjetivas de inquietação ou de estar mais lento.
6. $\quad$ Fadiga ou perda de energia quase todos os dias.
7. Sentimento de inutilidade, culpa excessiva ou inadequada (pode ser delirante) quase todos os dias. Não meramente autorrecriminação ou culpa por estar doente.
8. Capacidade diminuída de pensar ou se concentrar, ou indecisão, quase todos os dias. Indicado por relato subjetivo ou observação feita por outros.
9. Pensamentos de morte recorrente. Ideação suicida recorrente sem um plano específico. Tentativa de suicídio ou plano específico para cometer suicídio.

B) Os sintomas não satisfazem os critérios para um episódio misto.

C) Os sintomas causam sofrimento clinicamente significativo ou prejuízo no funcionamento social, ocupacional ou em outras áreas importantes da vida do indivíduo.

D) Os sintomas não se devem aos efeitos fisiológicos diretos de uma substância (abuso de drogas ou medicamentos) ou de uma condição médica geral, exemplificado por hipotireoidismo.

E) Os sintomas não são mais bem explicados por luto e são caracterizados por acentuado prejuízo funcional, preocupação mórbida com desvalia, ideação suicida, sintomas psicóticos ou retardo psicomotor.

Fonte: Manual Diagnóstico e Estatístico de Transtornos Mentais: DMS-5. APA (2014).

Nota-se que o diagnóstico se dá de maneira subjetiva, dependendo da observação do paciente sobre si mesmo ou da observação de terceiros, como familiares e amigos. A subjetividade se estende ao médico psiquiatra, que realiza entrevistas com o paciente, em busca de dados do seu cotidiano que demostrem que ele se encontra com transtorno depressivo. Dessa forma, a visão e a opinião do profissional a respeito do seu paciente influenciam no seu julgamento, podendo avaliar os relatos do paciente com uma magnitude diferente do real ou distinta da opinião de outros médicos, diferenciando possíveis diagnósticos. Em suma, o processo para se diagnosticar depressão se dá de forma subjetiva, sendo o resultado de fatores avaliados por seres humanos passível de erros. Contudo, é claro que a avaliação por meios dos critérios e sintomas é essencial para um diagnóstico, porém, seria ideal que existisse algo complementar a isso, na busca de um resultado mais preciso (DIAS, 2017). 


\section{Marcadores inflamatórios como biomarcadores da depressão}

Como já explicado anteriormente, o diagnóstico da depressão é subjetivo e baseado no DSM. Diante disso, novas pesquisas demonstram que a inflamação relacionada à depressão pode ser útil ao diagnóstico da doença. Os níveis dos marcadores inflamatórios supracitados seriam avaliados em pacientes com sintomas de depressão para diagnóstico, para prever opções de tratamento, seu acompanhamento e sua evolução e até antecipar o aparecimento da doença (FREITAS, 2017). Os biomarcadores seriam utilizados majoritariamente pelo médico psiquiatra para diagnóstico, sendo uma forma mais objetiva e definida em relação ao método atual de entrevistas (BACELAR JÚNIOR et al., 2016).

“Um biomarcador é um indicador de um processo biológico normal, processo patológico ou resposta farmacológica a uma intervenção terapêutica" (BACELAR JÚNIOR et al., 2016). É uma variação de uma substância dentro do nosso organismo que pode apontar para um diagnóstico de certa doença, por exemplo. Há uma relação entre o sistema imune com a depressão, principalmente durante um processo inflamatório, que pode afetar o bom funcionamento químico do cérebro (MENEZES, 2015). Uma variação de biomarcadores inflamatórios específicos ou o conjunto de vários poderia ser útil para o diagnóstico objetivo de transtorno depressivo, somando aos aspectos clínicos observados na doença, porém a identificação de moléculas que possam ser utilizadas como biomarcadores para a depressão é muito complicada devido à fisiopatologia diversificada e ainda não compreendida por completo da doença e à inacessibilidade ao cérebro para estudos (LIRA, 2016).

Os biomarcadores também poderiam ser utilizados para a descoberta de novos medicamentos, uma vez que ainda há uma grande demanda de novas drogas, visto que os fármacos utilizados atualmente não são de extrema eficácia, haja vista que "alguns sintomas não podem ser adequadamente resolvidos mesmo em pacientes que experimentam uma boa resposta terapêutica global" (BACELAR JÚNIOR et al., 2016).

A avaliação de proteínas, de citocinas, dos níveis periféricos de mRNA, da análise do padrão de sono e das técnicas de neuroimagem tem sido estudada como potenciais biomarcadores clínicos da depressão e seria utilizada em conjunto, uma vez que isso aumentaria a especificidade e a sensibilidade para o diagnóstico (BACELAR JÚNIOR et al., 2016). No entanto, devido à depressão ser uma doença ainda não completamente compreendida, com diferentes sintomas e efeitos colaterais, as pesquisas sobre os marcadores ainda não são conclusivas.

\section{O papel dos antidepressivos na neuroinflamação}

Os antidepressivos são utilizados em larga escala e estão entre os remédios mais vendidos no mundo. Há diversas classes e a maioria tem seu princípio de ação fundamentado na hipótese monoaminérgica, que leva ao aumento do nível de monoaminas na fenda sináptica, elevando o humor. Contudo, como citado anteriormente, as drogas atuais não possuem eficácia em uma parcela dos pacientes e nem sempre é capaz de eliminar todos os sintomas. 
Nesse contexto, os marcadores inflamatórios, estudados como biomarcadores, têm sido alvo de pesquisas que analisam a eficácia do antidepressivo de acordo com os níveis séricos de marcadores inflamatórios, uma vez que foram demonstrados em estudos que o uso desses fármacos é capaz de alterar os níveis de marcadores inflamatórios, variando com a classe de medicamento utilizada (MENEZES, 2015). Foi identificado que o tratamento com ADTs (antidepressivos tricíclicos) promovia a redução nos níveis de TNF- $\alpha$ e IL-1 $\beta$ (CORRADI et al., 2017). Porém, em outro estudo é identificado o aumento dos níveis de marcadores inflamatórios durante o tratamento com ADT (MENEZES, 2015). Já quando o medicamento utilizado é um ISRS (inibidor seletivo de recaptação de serotonina), é vista a redução de marcadores como IL-1 $\beta$, TNF- $\alpha$ e PCR, o que demonstra responsividade da depressão ao tratamento com ISRS (CORRADI et al., 2017).

Diante disso, Corradi et al. (2017) levantam a hipótese de que os níveis basais de marcadores inflamatórios podem identificar a resposta ao antidepressivo, logo a sua eficácia, o que melhoraria a prescrição de um fármaco que realmente iria funcionar para o paciente. Em contrapartida, outros estudiosos, como Menezes (2015), afirmam que a inflamação vista no uso de antidepressivos teria relação a outros fatores referentes a comorbidades da depressão, como uso excessivo de álcool e tabagismo, ou efeitos colaterais dos fármacos, como as doenças cardiovasculares, obesidade e outros.

\section{Outros biomarcadores para a depressão}

Alguns estudos já foram realizados na busca de um biomarcador não inflamatório para a depressão, que poderia auxiliar no diagnóstico e na avaliação do curso do tratamento. Lira (2016) analisou a quantidade do hormônio cortisol na saliva de homens e mulheres ao despertar. A principal ação desse hormônio é "a sua capacidade de aumentar a taxa de glicose sanguínea durante o processo de hipoglicemia" (LIRA, 2016). Além disso, o autor relata que o cortisol possui certa influência no sistema nervoso, envolvendo-se em diversos processos: na memorização, no processamento de informações, nos padrões de humor, na motivação e na aprendizagem. Essa ação se dá por conta da modulação exercida pelo cortisol nos neurotransmissores, segundo $o$ autor.

Em seu estudo, com uma amostra de 20 mulheres e seis homens diagnosticados com depressão maior (nenhum paciente estava fazendo uso de antidepressivos) e um grupo controle de 22 mulheres e 17 homens, Lira (2016) colheu a saliva dos voluntários ao despertar e levou as amostras para o laboratório. As diferenças entre os sexos e entre os pacientes deprimidos e saudáveis não foram significativas, porém notouse uma certa contradição em relação aos sexos. Homens deprimidos possuíam uma maior quantidade de cortisol na saliva do que homens saudáveis e mulheres deprimidas possuíam uma menor quantidade em relação às mulheres saudáveis. Notou-se, também, que quanto maior o grau de depressão, menor a quantidade de cortisol salivar em mulheres com depressão. Infelizmente, não foi possível demostrar essa relação nos voluntários homens, por conta de perdas de amostras e exclusão de alguns indivíduos. A pequena população da pesquisa de Lira (2016) é outro viés, não garantindo que os resultados encontrados sejam certos em relação à uma população maior. 
Outra possível opção seriam os chamados microRNAs (miRNAs), que são pequenos RNAs reguladores da expressão e função dos RNAs mensageiros (mRNA), atuando sobre a expressão genética pós-transcrição e associando-os a diversas patologias (FÉLIX, 2018). Segunda a autora, no início da sua descoberta, os miRNAs foram considerados moléculas intracelulares, porém, foi detectada sua presença fora das células do organismo, estando presentes no plasma, na urina e na saliva humanas. Por conta disso, poderiam "ser utilizados como biomarcadores no diagnóstico, avaliação de tratamento e como tratamento da depressão" (FÉLIX, 2018).

Existem diversos tipos de miRNAs e, segundo a revisão literária da autora, os "mais estudados e com resultados concordantes são os miR-24-3p, miR-132, miR-182 e miR-425-3p" e encontram-se em níveis elevados em comparação com controles saudáveis. Acredita-se que o miR-132 esteja associado à regulação da plasticidade neuronal, memória cognitiva e a diminuição dos níveis do fator neurotrófico derivado do cérebro, sendo um fator importante no desenvolvimento da depressão (FÉLIX, 2018).

Félix (2018) explica que é possível utilizar os microRNAs na avaliação do tratamento terapêutico da depressão, avaliando os níveis de miRNAs antes do início do tratamento e com uma nova medição após oito semanas de uso do(s) antidepressivo(s). Nos estudos citados pela autora, houve diminuição, aumento e não alteração dos níveis dessas pequenas moléculas de RNAs circulantes.

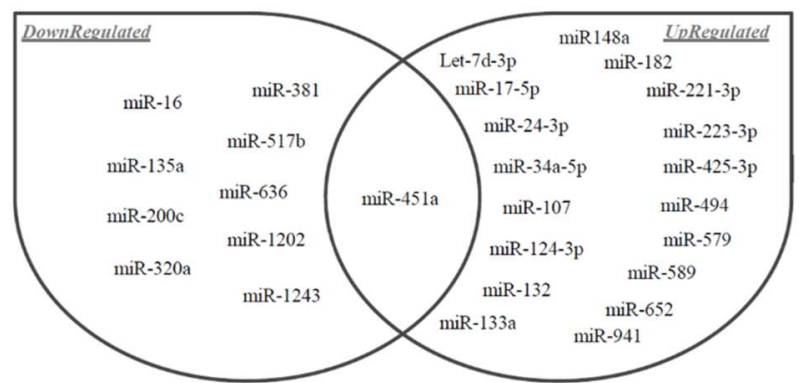

Figura 3: Principais microRNAs para diagnóstico da depressão.

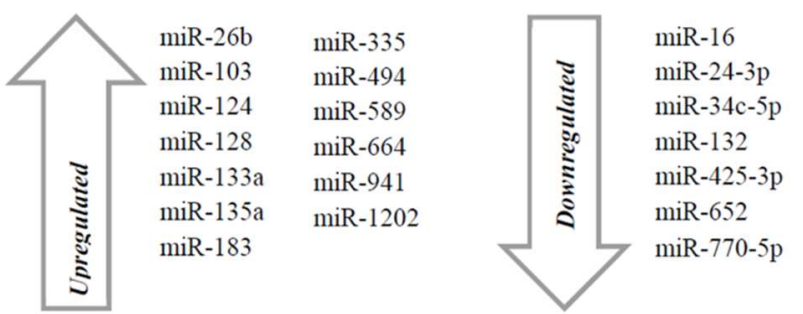

Figura 4: Principais microRNAs no tratamento com antidepressivos.

Fonte: Félix (2018)

Sousa (2018) foi mais além e analisou o papel dos microRNAs associados a exossomos. Esses últimos são vesículas resultantes da invaginação da membrana interna da célula, constituídos por RNAs mensageiros (mRNAs), microRNAs, proteínas intracelulares e lipídeos transmembranas. Eles são secretados pela célula de origem e migram através do organismo até as células-alvo para alterar sua fisiologia. Os exossomos enriquecidos de mRNAs e microRNAs se fundem com a membrana da célula-alvo e são endocitados e consequentemente traduzidos, resultando em proteínas que controlam as funções celulares (mRNAs) e a expressão gênica (microRNAs) (SOUSA, 2018).

Na revisão de Sousa (2018), quatro estudos envolvendo microRNAs e exossomos foram analisados, concordando com Félix (2018) no que diz respeito ao miR-132 e miR-182, ambos encontrados no sangue de controles saudáveis e pacientes com depressão. Para ambos os autores, esses dois tipos de microRNAs estão ligados à regulação do fator neurotrófico derivado do cérebro. 
Os miRNAs estão envolvidos na manifestação da doença e no efeito terapêutico dos antidepressivos. O miR-183, por exemplo, "gera um aumento da produção e liberação de cortisol” (SOUSA, 2018), descrito anteriormente como um hormônio capaz de influenciar no bom funcionamento do sistema nervoso. O miR16 afeta negativamente a serotonina, neurotransmissor alvo dos antidepressivos da classe ISRS (inibidores seletivos de recaptação de serotonina), dificultando o tratamento com esse tipo de fármaco.

\section{CONCLUSÕES}

Ao fim desta discussão acerca do papel dos marcadores inflamatórios na depressão, chegamos à conclusão de que existem evidências marcantes de que esses marcadores sofrem alterações significativas, sendo alterações de caráter aumentativo ou diminutivo, em pessoas que apresentam sintomas depressivos. Dessa forma, podem ser ótimos alvos de pesquisas visando sua utilização como biomarcadores de diagnóstico, de tratamento, de resposta do tratamento e de prevenção. Além disso, o estilo de vida e as doenças subjacentes também foram recorrentes como causadores do aumento nos níveis dos marcadores inflamatórios, o que demonstra que esses fatores estariam relacionados à etiologia da depressão. É importante salientar que são necessários novos estudos, de preferência com grandes amostras, que esclareçam a relação do sistema imune e da inflamação com a desregulação do sistema nervoso e o desenvolvimento da depressão.

\section{REFERÊNCIAS}

APA. American Psychiatric Association. Manual de Diagnóstico e Estatística de Distúrbios Mentais: DSM-5. 5 ed. Porto Alegre: Artmed, 2014.

AQUINO, C. C.. Efeito das dietas hipoproteica e hiperlipídica em marcadores de estresse oxidativo, inflamação e permeabilidade da barreira hematoencefálica no hipocampo e comportamento de ansiedade. Tese (Doutorado em Ciências Médicas) - Universidade Federal do Ceará, Fortaleza, 2019.

BACELAR JÚNIOR, A. J.; BACELAR, L. F. F.; RIBEIRO, F. F.; ALMEIDA, N. A. S.; SILVA, S. L.. Imunologia do sofrimento: o estudo da depressão como um fenômeno neuroimunológico e o uso de biomarcadores periféricos associados com predisposição, diagnóstico e prognóstico da depressão. Brazilian Journal of Surgery and Clinical Research, Cianorte, v.13, n.1, p.97-105, 2016.

CORRADI, M. A.; LISBOA, A. B.; JUNIOR, R. F.. Inflammatory markers as predictive factors for selective serotonin reuptake inhibitors (SSRI) antidepressant effect. Revista de Medicina, São Paulo, v.96, n.2, p.103-115, 2017. DOI: http://dx.doi.org/10.11606/issn.1679-9836.v96i2p103-115

DIAS, N. S.. Estudo de marcadores inflamatórios em idosas deprimidas. Dissertação (Mestrado em Medicina Molecular) - Universidade Federal de Minas Gerais, Belo Horizonte, 2017.

FÉLIX, A. R. L.. MicroRNAs no sangue como biomarcadores da Depressão Major: diagnóstico e avaliação do tratamento.
2018. Dissertação (Mestrado Integrado em Ciências Farmacêuticas) - Universidade de Coimbra, Coimbra, 2018.

FREITAS, T. H.. Citocinas e quimiocinas como biomarcadores terapêuticos na depressão: revisão sistemática e metaanálise. Tese (Doutorado em Ciências Médicas) Universidade Federal do Ceará, Fortaleza, 2017.

LEMOS, J. G.. Avaliação do perfil inflamatório, integridade da barreira hematoencefálica e sequelas cognitivas na vida adulta em modelo experimental de meningite neonatal por streptococcus agalactiae. Tese (Doutorado em Ciências da Saúde) - Universidade do Extremo Sul Catarinense, Criciúma, 2015.

LIRA, R. A.. Análise do cortisol salivar ao despertar, de homens e mulheres, com depressão: biomarcador da depressão maior. Monografia (Bacharelado em Odontologia) - Universidade Federal do Rio Grande do Norte, Natal, 2016.

MACHADO, A. P. R.; CARVALHO, I. O.; SOBRINHO, H. M. R.. Neuroinflamação na doença de Alzheimer. Revista Brasileira Militar de Ciências, Goiânia, v.6, n.14, p.30-38, 2020. DOI: http://doi.org/10.36414/rbmc.v6i14.33

MENEZES, S. T.. Depressão atual, uso de antidepressivo e marcador inflamatório: estudo longitudinal de saúde do adulto (ELSA-Brasil). Dissertação (Mestrado em Ciências Aplicadas à Saúde do Adulto) - Universidade Federal de Minas Gerais, Belo Horizonte, 2015.

SCHMITT JÚNIOR, A. A.; ALVES, L. P. C.; ROCHA, N. S. Marcadores inflamatórios séricos em doença mental grave: 
diminuição de interleucinas 2 e 6 após tratamento de pacientes internados. In: SEMANA CIENTÍFICA DO HOSPITAL DE CLÍNICAS DE PORTO ALEGRE, 38. Anais. Porto Alegre: Hospital de Clínicas de Porto Alegre, 2018. p.313.

SOBRAL, R. Selectividade da barreira hematoencefálica: inibidores das metaloproteinases. Dissertação (Mestrado Integrado em Ciências Farmacêuticas) - Instituto Superior de Ciências da Saúde Egas Moniz, Almada, 2018.

SOUSA, J. V. V.. Estudo do papel dos MicroRNAs em indivíduos com depressão: revisão sistemática. Monografia
(Bacharelado em Biomedicina) - Universidade Federal do Estado do Rio de Janeiro, Rio de Janeiro, 2018.

VARATHARAJ, A.; GALEA, I.. The blood-brain barrier in systemic inflammation. Brain, Behavior, and Immunity, v.60, p.1-12, 2017

WHO. World Health Organization. Depression and other common mental disorders: global health estimates. Geneva: WHO, 2017.

A CBPC - Companhia Brasileira de Produção Científica (CNPJ: 11.221.422/0001-03) detém os direitos materiais desta publicação. Os direitos referem-se à publicação do trabalho em qualquer parte do mundo, incluindo os direitos às renovações, expansões e disseminações da contribuição, bem como outros direitos subsidiários. Todos os trabalhos publicados eletronicamente poderão posteriormente ser publicados em coletâneas impressas sob coordenação da Sustenere Publishing, da Companhia Brasileira de Produção Científica e seus parceiros autorizados. Os (as) autores (as) preservam os direitos autorais, mas não têm permissão para a publicação da contribuição em outro meio, impresso ou digital, em português ou em tradução. 